\title{
Flood Risk Assessment on Selected Critical Infrastructure in Kota Marudu Town, Sabah, Malaysia
}

\author{
Janice Lynn Ayog ${ }^{1,2^{*}}$, Felix Tongkul ${ }^{2}$, Abdul Karim Mirasa ${ }^{1,2}$, Rodeano Roslee ${ }^{2}$, and \\ Salinah Dullah ${ }^{1}$ \\ ${ }^{1}$ Faculty of Engineering, Universiti Malaysia Sabah, Jln UMS, 88400 Kota Kinabalu, Sabah, \\ Malaysia \\ ${ }^{2}$ Natural Disaster Research Centre, Universiti Malaysia Sabah, Jln UMS, 88400 Kota Kinabalu, \\ Sabah, Malaysia
}

\begin{abstract}
This study investigates the risk of flood on selected critical infrastructure in a flood-prone catchment in Sabah, Malaysia. Kota Marudu, located in the Bandau floodplain, one of the Sabah's northern water catchments, was selected as the study site due to its frequent flood occurrence and large floodplain coverage. Two of its largest rivers, namely Sungai Bongon and Sungai Bandau, tends to flood during rainy season and cause temporary displacements of thousands of people living in the floodplain. A total of 362 respondents participated in the questionnaire survey in order to gather information on historical flood occurrence. Three flood depth groups were determined, which are 1) less than 0.3 meter, 2) 0.3 - 0.6 meter and 3) more than 0.6 meter, while three categories of critical infrastructure were defined, namely transportation system, communication system and buildings. It is found that the transportation system encounters the most severe impact as flood inundation increases, where $92 \%$ of the respondents believe that the transportation access should be abandoned when flood depth is more than $0.6 \mathrm{~m}$. The findings of this study will be used for detailed risk assessment, specifically on the vulnerability of the critical infrastructures to flood in this floodplain.
\end{abstract}

\section{Introduction}

The world community faces many risks from flooding as the pattern of floods across all continents have been changing, becoming more frequent, intense and unpredictable for local communities. Flooding is the most devastating type of natural disasters that hits human lives around the world. When flood occur in developing nations, they can effectively wipe out the entire investments in infrastructure and the personal wealth of many people, not to forget loss of lives, physical injuries, illness and psychological trauma that result from this disaster. Climate change may exacerbate the damage caused by extreme events, such as floods [1]. Critical infrastructure, which comprises of

\footnotetext{
*Corresponding author: jay@ums.edu.my
} 
transportation and communication system, water and power lines and public institutions including schools, halls and health clinics, plays important roles as it includes the basic facilities, services and installations needed for the functioning of a community or society. Besides daily needs, it is also crucially important on the occasions of natural disasters, which refer to floods in this study, as the infrastructure will be used for safe road access for evacuations, to offer temporary refuge for the displaced victims, to provide medical treatments for injuries and many more. In fact, one of the essential parts in post-disaster reconstruction is rebuilding facilities and infrastructures for those affected, which includes critical infrastructures [2].

Flood events in the past revealed the need to safeguard infrastructure from destructive threats and prompted the need to work on preparedness, response and recovery plans associated to infrastructure safety. In order to gain the capacity to be prepared to avoid and manage hazardous flood situations, it is fundamental to understand and analyse the vulnerability of critical infrastructure and associated buildings. Through the vulnerability assessment, effective measurements for flooding can be improved and thus minimizes the damaging impacts done on critical infrastructure which in return minimizes the disruption done to the community as critical infrastructure is essential to public health and safety, nation's security as well as economic vitality.

\subsection{Flood Risk, Hazard and Vulnerability}

It is fundamentally important to understand the nature of flood risk in order to be able to future-proof human lives as well as economic damages and losses against the rapidly changing circumstances of the twenty-first century. Kates and Kasperson [3] considered that there are three distinct steps for risk assessment which include the identification of hazards, the estimation of risks and the evaluation of the associated consequences of the derived risk. However, Ologunorisa and Abuwua [4] believed that post-audits of all risk exercises should be considered as another additional step in order for sound risk management to occur.

Risk can be expressed mathematically as shown in Equation (1):

$$
\text { Risk }=\text { Hazard } x \text { Vulnerability } x \text { Exposure }
$$

Based on Equation (1), hazard is the potentially harmful event magnitude refers to both physical and statistical dimension of inundation such as the return period, flow velocity, extent and depth of a flood [5]. Past experience and records are taken into account to determine hazard. Exposure is the intensity, frequency and degree of human or assets exposed to an agent. The exploitations of flood prone areas due to the tremendously increased world's population have induced more exposure of people, property and infrastructure to the susceptibility of inundation. In the event of an inundation with no building contained in that flooded area, risk again does not exist owing to the fact that exposure is absent.

Vulnerability in the context of flood, is the extent to which a system is susceptible to floods due to exposure, a perturbation, in conjunction with its capacity or incapacity to be resilient, which is to cope, to recover or to adapt [6].

Linnekamp et al. [7] performed a research assessing household vulnerability to flooding as a result of climate change in two low elevation coastal zone cities in Caribbean. The authors intended to examine the perceptions of household of flood risks and considered vulnerability of households as the combined results of social-economic in entitlements and exposure to flooding and extreme rainfall. Both survey and interview were carried out during the research. The cities were compared in terms of their exposure, resistance and 
adaptive capacity to flooding. Balica et al. [8] has carried out a study in establishing a flood vulnerability index of 9 different coastal cities around the world, which took into account the hydro-geological, social, economic and politico-administrative components.

\subsection{Background of Study Area \& Research Problem}

Malaysia, due to its geographical location with 189 water basins and an average rainfall over $2000 \mathrm{~mm}$ per year, is prone to suffer from floods and flash floods especially during cyclical monsoon cold surge episodes which are characterized by extreme rainfall from roughly November to February [9]. Sabah is not excluded from the appalling effects of flooding. Nine districts in Sabah are identified as flood-prone regions according to the report made by the Department of Irrigation \& Drainage Sabah in 1996. Kota Marudu is listed as one of them with approximately 8.0 square kilometers of flood-prone area.

Kota Marudu is unique as it is shaped like a flat-floored amphitheater, where most areas upstream are a part of the Kinabalu National Park (in which Mount Tambayukon, the third highest mountain in Malaysia is located). Due to this natural priviledge, vast areas of the upper catchment are intended to be gazetted as a water protection area. This should have resolved the flooding problems, however, illegal logging upstream and the issues of land acquisition by the natives (of which overlapped with the proposed water protection zone) have challenged the effort to effectively mitigate the flood woes. While these issues need to be tackled in one way or another, an alternative approach needed to be looked into to mitigate the annual flooding cases; hence, by developing flood vulnerability index, the critical infrastructures needed for the emergency and evacuation plans of the flood victims can be safeguarded.

Kota Marudu suffered from frequent occurrences of inundations which happen at least once a year. The flooding occurrences were contributed by the heavy flows of Sungai Bongon and Sungai Bandau, which are the main rivers in Kota Marudu. The critical infrastructures in Kota Marudu play very important roles in the flood events. During these seasonal, but extreme high flows, a huge number of villagers are displaced and evacuated to the nearest temporary relief centres and refuges, such as schools or halls. There were 2,027 people from 448 families in 16 villages were forced to abandon their homes and moved to nine temporary relief centres due to floods. The critical situations were further exacerbated by the inundation of road system as vehicles were no longer able to safely evacuate victims to a secure place. Emergency response teams swiftly took speed boats as alternatives to promptly send the victims to temporary shelters.

It is apparent that the safety of critical infrastructures is vital for flood emergency approaches in Kota Marudu. Owing to this, the vulnerability of critical infrastructures has to be analysed and assessed to ensure of its effectiveness for flood emergency plan in Kota Marudu. International concern about the disastrous flooding events has risen as the associated economic damage is significant. Hence, many countries have adopted the approaches of flood risk management as stimulated by severe catastrophic floods around the world [10]. The relentless upward global trend in vulnerability to flooding, resulted losses and threats from potential impacts of climate change on flood frequency represent the supporting factors that contribute to the emerging of flood risk management.

\section{Research Methodology}

This study intends to investigate the perception of the local residents pertaining to the risk of selected critical infrastructure to floods in Kota Marudu, Sabah, Malaysia. A questionnaire-based survey was done to gather the responses of the locals on the risk of flood inundation of these infrastructure based on a range of flood depths. The local 
community's perception on the flood damage, especially those who have encountered flood almost every year will shed unique insight of what the actual damage could have been, in order for a detailed vulnerability assessment of the affected critical infrastructure can be done accurately.

In the questionnaire survey, 362 respondents of the local residents were gathered through convenient sampling. Information regarding the vulnerability of existing critical infrastructures in Kota Marudu was acquired effectively through the knowledge and past experience of the local residents in the study area. The questionnaire was concentrated on the vulnerability of the three general critical infrastructures - transportation system, communication system and buildings. Three range of flood depths were determined, namely 1) less than 0.3 meter, 2) $0.3-0.6$ meter and 3) more than 0.6 meter. A structured non-disguised questionnaire was prepared where questions were presented in pre-arranged order and the respondents were well informed of the purpose of the survey. The targeted survey respondents are those in the age of 15 and above.

The questionnaire consists of two parts. The first part consists of two demographic questions and four flood related questions. The second part required the respondents to assess the flood risk of the selected critical infrastructure based on three range of flood depths. Table 1 to Table 3 provide the descriptions of the flood risk based on the previously-mentioned three critical infrastructure categories.

Table 1. Flood risk and impact on the transportation system.

\begin{tabular}{|c|c|c|}
\hline Risk & Availability of Transportation & Description \\
\hline Severe & Cannot travel outdoor & Transportation access abandoned \\
\hline Critical & Very hard to travel outdoor & Very limited transportation access \\
\hline Moderate & Hard to travel outdoor & Limited transportation access \\
\hline Light & Minor difficulties to travel outdoor & Slightly transportation access \\
\hline None & Free to travel outdoor & Full transportation access \\
\hline
\end{tabular}

Table 2. Flood risk and impact on the communication system.

\begin{tabular}{|c|c|c|}
\hline Risk & Availability of Transportation & Description \\
\hline Severe & $\begin{array}{c}\text { Cannot be contacted (both phone and } \\
\text { face-to-face) }\end{array}$ & No communication access \\
\hline Critical & Very limited contact (via phone only) & Very limited communication access \\
\hline Moderate & $\begin{array}{c}\text { Limited contact (face-to-face with } \\
\text { major difficulties) }\end{array}$ & Limited communication access \\
\hline Light & $\begin{array}{c}\text { Good contact (face-to-face with minor } \\
\text { difficulties) }\end{array}$ & $\begin{array}{c}\text { Slightly limited communication } \\
\text { access }\end{array}$ \\
\hline None & Not affected & Full communication access \\
\hline
\end{tabular}

Table 3. Flood risk and impact on the buildings.

\begin{tabular}{|c|c|}
\hline Risk & Description \\
\hline Severe & More than $50 \%$ of the structure destroyed \\
\hline Critical & $30 \%$ to $50 \%$ of the structure destroyed \\
\hline Moderate & $5 \%$ to $30 \%$ of the structure destroyed \\
\hline Light & Less than $5 \%$ of the structure destroyed \\
\hline None & Structure not affected by flood \\
\hline
\end{tabular}




\section{Results and Discussion}

Fig. 1 shows the distribution of the respondents based on the age groups. It can be seen that the respondents participated in the questionnaire were distributed rather evenly - each age group consists of $20-30 \%$ of the total number of respondents. Majority of the respondents are aged between $45-65$ years old $(30 \%)$, while the least number of representative of age group is between $26-45$ years old $(21 \%)$. Fig. 2 shows the distribution of respondents based on occupation. It is found that $42 \%$, which is the majority of the respondents, were farmers while the second largest group is the student group.

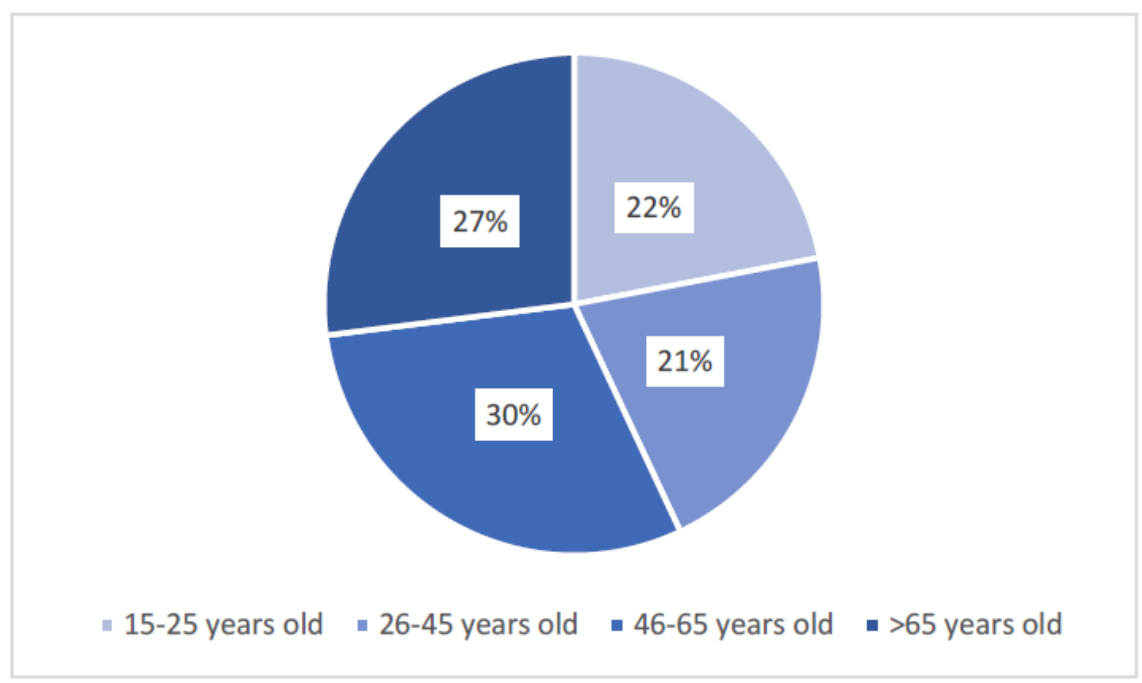

Fig. 1. The distribution of respondents based on the respondents' age group.

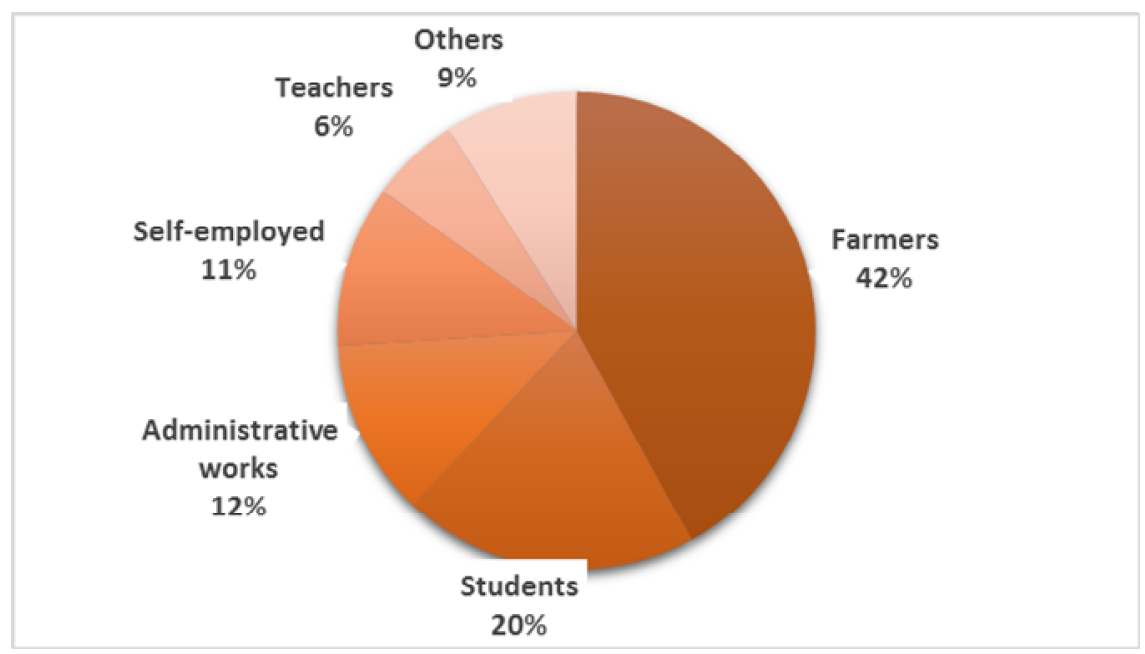

Fig. 2. The distribution of respondents based on the respondents' occupation.

Fig. 3 shows the responses on flood risk for transportation system. This study reveals that at a flood depth of $0.3 \mathrm{~m}$, about $79.3 \%$ of the respondents has a perception that the 
impact is light. At a flood depth between $0.3 \mathrm{~m}$ to $0.6 \mathrm{~m}$, approximately $69.9 \%$ of the respondents perceived that the flood impact is at a moderate level, while a majority of the respondents $(91.7 \%)$ think that flood could cause severe impact. This finding shows a trend where flood impact increases with flood depth.

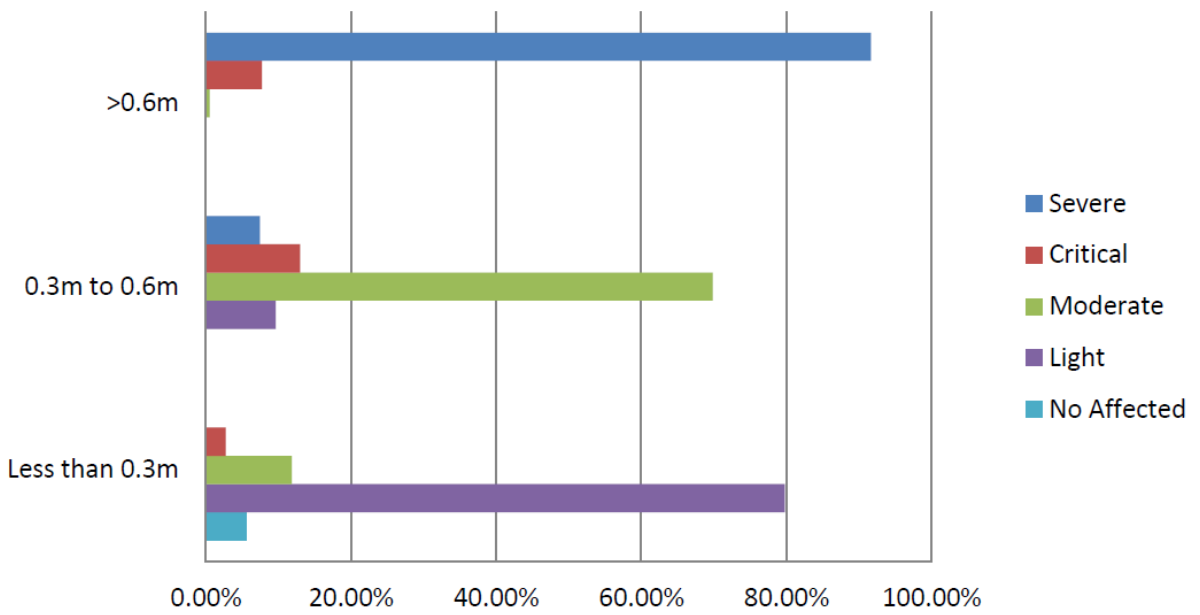

Fig. 3. Responses on flood risk for transportation system.

Different flood depth causes varying impact to the transportation system, which has direct exposure to the impact of flood. According to Heberger et al. [11], an increase of $1.4 \mathrm{~m}$ in sea level will cause double mileage under inundation, which indicates that transportation is affected due to flood. In Semarang, Indonesia, Marfai et al. [12] found that an increase of flood level about $0.5 \mathrm{~m}$ will cause disruption of accessibility and road.

Communication is another aspect which is frequently affected by flood. This aspect has been incorporated into this study and the result revealed that the effect of flood on the communication system in Kota Marudu increases with inundation. From Fig. 4, at flood depth less than $0.3 \mathrm{~m}$, most of the respondent feels that the impact on communication is light, meaning that less flood impact is experienced. This situation changed as the flood depth increases. At flood depth between $0.3 \mathrm{~m}$ to $0.6 \mathrm{~m}, 52.3 \%$ of total respondent perceived that flood impact is at moderate level. The impact raised to critical stage when the flood level is more than $0.6 \mathrm{~m}$, as expressed by approximately $55.5 \%$ of the total respondents. As with transportation, it can be observed that communication system is greatly affected by flood depth. 


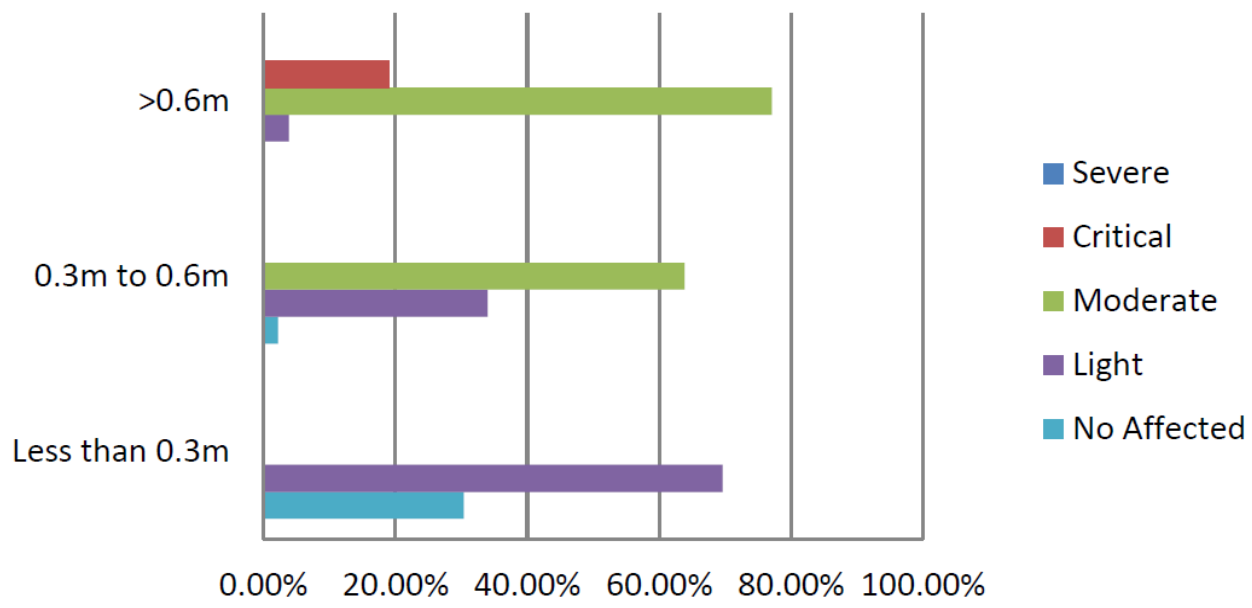

Fig. 4. Responses on flood risk for communication system.

Fig. 5 shows the response on flood risk on buildings. Building damages with its relation to flood is another aspect was investigated in this study. It is found that at a flood depth of $0.0 \mathrm{~m}$ to $0.6 \mathrm{~m}$, building damage were perceived as light, while a flood depth beyond $0.6 \mathrm{~m}$ is thought to cause moderate impact to the building damage.

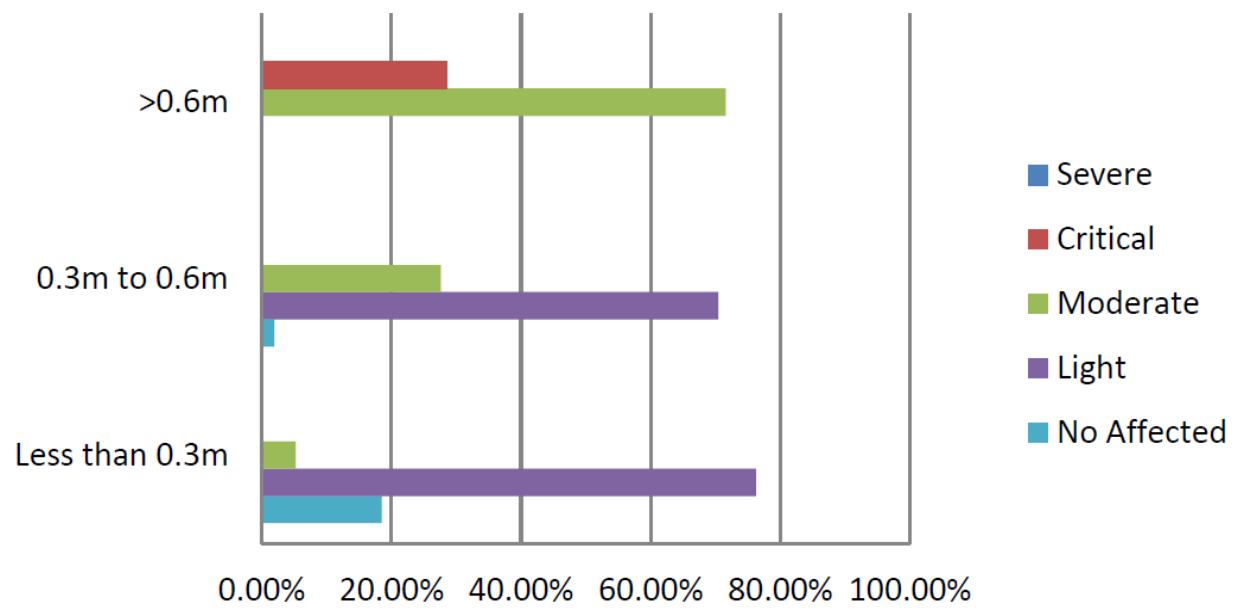

Fig. 5. Responses on flood risk for buildings.

According to Tu and Tingsanchali [13], most building is not much affected by flood depth less than $0.24 \mathrm{~m}$ and only slightly affected between $0.5 \mathrm{~m}$ to $1.5 \mathrm{~m}$ of depth. Higher impact is experienced for flood depth between $1.5 \mathrm{~m}$ to $3.0 \mathrm{~m}$. Heberger et al. [11] states that the property in bay area is particularly vulnerable to flood impact due to sea level rise which could cause coastal floods. The location of Kota Marudu town, which is located at Marudu Bay may share the same flooding characteristics as reported by Heberger et al. [11]. 


\section{Conclusion}

In this study, the severity of flood impact on three social aspects namely transportation system, communication system and building damages were investigated. The responses gathered indicate that as the flood depths increases, the impact of flood gradually becomes critical. Transportation system encounters the most severe impact, where transportation access will be abandoned when the flood depth reaches above $0.6 \mathrm{~m}$. This shows that transportation system is very sensitive to floods. Theoretically, flood issues such as these would require structurally and/or non-structurally reinforcing the critical infrastructures studied in this research, however, due to the complex nature of flood and as the results are solely based on the perception of the respondents alone, further analysis will be done through the development of flood models to corroborate the accuracy of the findings in this study and suggest appropriate solution to mitigate the impacts.

This study is financially supported by the Malaysian Ministry of Education Fundamental Research Grant Scheme (FRGS) Grant No. FRG0421-TK-1/2015. The authors would like to thank Mr. Vun Siew Fui, Ms. Chin Su Vun and Ms. Nicole Lee Siew Len for their significant contributions in this research.

\section{References}

[1] A. W. Salami, A. A. Mohammad and O. G. Okeola, Evaluation of climate change impact on runoff in the Kainji Lake Basin using Artificial Neural Network Model (ANN), Malaysian J. of Civil Eng, 26 (1), 35-50, (2014)

[2] C. E. Farahdilla, S. A. Mansur and A. Abdullah, Common issues in post-disaster reconstruction, Malaysian J. of Civil Eng, 25 (2), 267-276, (2013)

[3] R. W. Kates and J. X. Kasperson, Comparative risk analysis of technological hazards (a review), Proceedings of National Academy of Science, 80, 7027-7038, (1983)

[4] T. E. Ologunorisa and M. J. Abuwua, Flood risk assessment: A review, J. of App. Sciences \& Environmental Management, 9(1), 57-63, (2005)

[5] H. Apel, G. T. Aronica, H. Kreibich and A. H. Thieken, Flood risk analyses - How detailed do we need to be?, Natural Hazards, 49 (1), 79-98, (2009)

[6] S. F. Balica, N. Douben and N. G. Wright, Flood vulnerability indices at varying spatial scale, Water Sci. \& Tech., 60 (10), 2571-2580, (2009)

[7] F. Linnekamp, A. Koedam and I.S.A. Baud, Household vulnerability to climate change: Examining perceptions of households of flood risks in Georgetown and Paramaribo, Habitat International, 35 (3), 447-456, (2011)

[8] S. F. Balica, N. G. Wright, F. van der Meulen, A flood vulnerability index for coastal cities and its use in assessing climate change impacts, Natural Hazards, 64 (1), 73-105, (2012)

[9] L. Juneng, F. T. Tangang, C. J. C. Reason, Numerical case study of an extreme event during 9-11 December 2004 over the east coast of Peninsular Malaysia, Met. and Atm. Physics, 98 (1-2), 81-98, (2007)

[10] J. W. Hall and E.C. Penning-Rowsell, Setting the Scene for Flood Risk Management, Flood Risk Sci. and Management, 1-16, (2011)

[11] M. Heberger, H. Cooley, P. Herrera, P. H. Gleick and E. Moore, Potential Impacts of Increased Coastal Flooding in California Due to Sea-level Rise, Climate Change, 109, 229-249, (2011) 
[12] M. A. Marfai, L. King, J. Sartohadi, S. Sudrajat, S. R. Budiani and F. Yulianto, The Impact of Tidal Flooding On A Coastal Community in Semarang, Indonesia, The Environmentalist, 28 (3), 237-248, (2008)

[13] V.U.T. Tu and T. Tingsanchali, Flood hazard and risk assessment of Hoang Long River basin, Vietnam, Proceedings of the International MIKE by DHI Conference, (2010) 